\title{
Comprehensive systematic review summary: Treatment of tics in people with Tourette syndrome and chronic tic disorders
}

Tamara Pringsheim, MD, MSc, Yolanda Holler-Managan, MD, Michael S. Okun, MD, Joseph Jankovic, MD, John Piacentini, PhD, Andrea E. Cavanna, MD, PhD, Davide Martino, MD, PhD, Kirsten Müller-Vahl, MD, Douglas W. Woods, PhD, Michael Robinson, Elizabeth Jarvie, MSW, LCSW, Veit Roessner, MD, and Maryam Oskoui, MD, MSc

Neurology ${ }^{\circledR}$ 2019;92:907-915. doi:10.1212/WNL.0000000000007467

\section{Abstract}

\section{Objective}

To systematically evaluate the efficacy of treatments for tics and the risks associated with their use.

\section{Methods}

This project followed the methodologies outlined in the 2011 edition of the American Academy of Neurology's guideline development process manual. We included systematic reviews and randomized controlled trials on the treatment of tics that included at least 20 participants (10 participants if a crossover trial), except for neurostimulation trials, for which no minimum sample size was required. To obtain additional information on drug safety, we included cohort studies or case series that specifically evaluated adverse drug effects in individuals with tics.

\section{Results}

There was high confidence that the Comprehensive Behavioral Intervention for Tics was more likely than psychoeducation and supportive therapy to reduce tics. There was moderate confidence that haloperidol, risperidone, aripiprazole, tiapride, clonidine, onabotulinumtoxinA injections, 5-ling granule, Ningdong granule, and deep brain stimulation of the globus pallidus were probably more likely than placebo to reduce tics. There was low confidence that pimozide, ziprasidone, metoclopramide, guanfacine, topiramate, and tetrahydrocannabinol were possibly more likely than placebo to reduce tics. Evidence of harm associated with various treatments was also demonstrated, including weight gain, drug-induced movement disorders, elevated prolactin levels, sedation, and effects on heart rate, blood pressure, and ECGs.

\section{Conclusions}

There is evidence to support the efficacy of various medical, behavioral, and neurostimulation interventions for the treatment of tics. Both the efficacy and harms associated with interventions must be considered in making treatment recommendations.

\author{
Correspondence \\ American Academy of \\ Neurology \\ guidelines@aan.com
}

\section{RELATED ARTICLE}

Practice guideline recommendations summary: Treatment of tics in people with Tourette syndrome and chronic tic disorders

Page 896

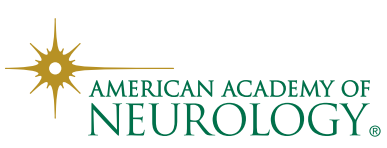

From the Department of Clinical Neurosciences, Psychiatry, Pediatrics and Community Health Sciences (T.P., D.M.), Cumming School of Medicine, University of Calgary, Alberta, Canada; Department of Pediatrics (Neurology) (Y.H.-M.), Northwestern University Feinberg School of Medicine, Chicago, IL; Departments of Neurology and Neurosurgery (M.S.O.), Fixel Center for Neurological Diseases, University of Florida, Gainesville; Department of Neurology (J.J.), Baylor College of Medicine, Houston, TX; Department of Psychiatry and Biobehavioral Sciences (J.P.), Semel Institute for Neuroscience and Human Behavior, University of California Los Angeles; Department of Neuropsychiatry (A.E.C.), BSMHFT, University of Birmingham and Aston University, UK; Department of Psychiatry, Social Psychiatry, and Psychotherapy (K.M.-V.), Hannover Medical School, Germany; Department of Psychology (D.W.W.), Marquette University, Milwaukee, WI; Massachusetts Chapter (M.R.), Tourette Association of America, Bayside, NY; Waisman Center (E.J.), University Center for Excellence in Developmental Disabilities, University of Wisconsin, Madison; Technische Universitaet Dresden (V.R.), Germany; and Departments of Pediatric and Neurology/ Neurosurgery (M.O.), McGill University, Montréal, Canada.

Go to Neurology.org/N for full disclosures. Funding information and disclosures deemed relevant by the authors, if any, are provided at the end of the article.

Approved by the Guideline Development, Dissemination, and Implementation Subcommittee on July 29, 2017; by the AAN Practice Committee on October 15, 2018; and by the AAN Institute Board of Directors on February 12, 2019.

This guideline was endorsed by the Child Neurology Society on September 4, 2018, and the European Academy of Neurology on September 5, 2018. 


\section{Glossary}

AAN = American Academy of Neurology; ADHD = attention-deficit/hyperactivity disorder; $\mathbf{C I}=$ confidence interval; $\mathbf{C O I}=$ conflict of interest; DBS = deep brain stimulation; GDDI = Guideline Development, Dissemination, and Implementation; rTMS = repetitive transcranial magnetic stimulation; $\mathbf{S M D}=$ standardized mean difference; $T$ S = Tourette syndrome; YGTSS = Yale Global Tic Severity Scale.

This article summarizes the findings of a systematic review, conducted as the foundation of an American Academy of Neurology (AAN) practice guideline on the treatment of tics in people with Tourette syndrome (TS) and chronic tic disorders. A companion article summarizes the assessment and treatment recommendations and suggestions for future research. The complete and unabridged practice guideline (systematic review, recommendations, and suggestions for future research) is available at links.lww.com/WNL/A883 and includes full details of the methodology used, including the risk of bias assessment for each study, meta-analysis, and confidence in evidence determinations; space restrictions precluded more detailed description in this article.

TS is a neurodevelopmental condition that is characterized by the presence of multiple motor tics and at least 1 vocal tic that persists for at least 1 year. ${ }^{1}$ Motor tics are defined as sudden, rapid, recurrent, and nonrhythmic movements. Vocal tics are essentially motor tics that involve the nasal or respiratory muscles, resulting in simple sounds such as sniffing, throat clearing or coughing, or complex vocalizations, including coprolalia, but they also may manifest with speech blocking or stuttering-like symptoms. Tics are often accompanied by specific behavioral symptoms. ${ }^{2,3}$ Persistent (chronic) motor tic disorder is characterized by the presence of motor tics only, which persist for more than 1 year. Persistent (chronic) vocal tic disorder is characterized by the presence of vocal tics only, which persist for more than 1 year. Epidemiologic studies that used current diagnostic criteria have consistently shown that the prevalence figures for TS in school children range from $0.4 \%$ to $1.5 \%$ across all cultures, while the prevalence of chronic tic disorders ranges from $0.9 \%$ to $2.8 \%{ }^{4}$ There are few population-based estimates of the prevalence of TS in adults; one recent population-based study found a prevalence of diagnosed TS of approximately 1 per $1,000 .^{5}$ TS and chronic tic disorders are believed to share a common neurobiological origin, and we use the abbreviation TS throughout the article to refer to all individuals with primary chronic tic disorders.

The majority of patients with TS, both in specialist clinics and in the community, report the presence of behavioral symptoms associated with their tics: most commonly obsessivecompulsive disorder (or obsessive-compulsive behavior) and

\section{$\oplus$ Supplemental Data}

Full measurement set

NPub.org/vsmv3e attention-deficit/hyperactivity disorder (ADHD). ${ }^{6}$ Lifetime prevalence of comorbid behavioral disorders is estimated to approach $90 \%{ }^{7}$ Patients with TS also report higher rates of impulse control, anxiety, and affective disorders compared with people in the general population. ${ }^{7,8}$ It is worth noting that the associated behavioral comorbidities often compromise the overall well-being of patients with TS to a much greater extent than tic severity., ${ }^{9,10}$

The purpose of this systematic review is to assess all randomized controlled trials that evaluate the efficacy of medical and behavioral treatments for tics, including neurostimulation, and the risks associated with their use. The systematic review was performed to develop recommendations pertaining to the treatments of tics in children and adults with TS or chronic tic disorders. Antipsychotic medications have been commonly prescribed for this purpose since the 1960s. The adverse effects associated with antipsychotic medications, including movement disorders such as acute and tardive dystonia, tardive dyskinesia, akathisia, and drug-induced parkinsonism, and metabolic adverse effects, such as weight gain, hyperlipidemia, and hyperglycemia, have led clinicians to search for other effective treatments. In recent years, there has been a resurgence in the interest in behavioral treatments and neuromodulation for tics, yielding expanding evidence in this area.

\section{Clinical questions}

The systematic review for this practice guideline addressed the following questions:

1. In children and adults with TS or a chronic tic disorder, which medical, behavioral, and neurostimulation interventions, compared with placebo or other active interventions, improve tic severity?

2. In children and adults with TS or a chronic tic disorder, what are the risks of harm, including weight gain, elevated prolactin levels, sedation, drug-induced movement disorders, hypotension, bradycardia, and ECG changes with medical treatments, compared with placebo or other active interventions?

\section{Description of the analytic process}

In May 2016, the Guideline Development, Dissemination, and Implementation (GDDI) Subcommittee of the AAN recruited a multidisciplinary panel to develop the guideline, including 9 physicians, 2 psychologists, and 2 patient representatives. The patient representatives are both associated with the Tourette Association of America. All panel members 
were required to submit online conflict of interest (COI) forms and copies of their curriculum vitae. All authors determined to have COI were not permitted to review or rate the evidence.

This evidence-based practice guideline follows the methodologies described in the 2011 edition of the AAN's guideline development process manual, ${ }^{11}$ as amended to include use of the revised scheme for classifying therapeutic articles, the GDDI Guideline Topic Nomination Process scoring tool, and the change in order of steps for external review.

\section{Study screening and selection criteria: Inclusion criteria for article selection}

We included systematic reviews and randomized controlled trials on the treatment of tics in individuals with TS or chronic tic disorders that included at least 20 participants (10 participants if a crossover trial), except for neurostimulation trials, for which no minimum sample size was required. To obtain additional information on drug safety, we included cohort studies or case series that specifically evaluated adverse drug effects in individuals with TS.

\section{Types of participants}

We included individuals with TS or chronic tic disorders of any age or sex.

\section{Types of intervention}

We included any medical, behavioral, or neurostimulation (e.g., transcranial magnetic stimulation, deep brain stimulation $[\mathrm{DBS}])$ intervention for tics.

\section{Comparison group}

We included studies that compared medical, behavioral, or neurostimulation treatments with placebo or other active treatments.

\section{Types of outcome measures}

We assessed the effect of all treatments on measures of tic severity and tic-related impairment. The preferred instrument for evaluation of tic severity and tic-related impairment was the Yale Global Tic Severity Scale (YGTSS), and when outcome results with this instrument were reported, they were used to calculate effect size. The YGTSS, the most extensively deployed rating scale for tics internationally, has displayed very good internal consistency, interrater reliability, and convergent and divergent validity. ${ }^{12}$ Weight gain was assessed through reported measurements in kilograms. Elevated prolactin levels were evaluated by assessing mean changes in prolactin levels between groups, or mean prolactin levels at endpoint between groups. Drug-induced movement disorders were based on assessments that used validated scales, including the Extrapyramidal Symptoms Rating Scale, Barnes Akathisia Scale, Simpson Angus Scale, or the Abnormal Involuntary Movement Scale, or by clinician report. Sedation was evaluated by patient/parent/clinician report and assessment. Hypotension and bradycardia were evaluated by assessing reported changes in systolic and diastolic blood pressure and heart rate with treatment and reported rates of presyncope and syncope. Reported ECG changes were also included.

The initial search was conducted in August 2016 and included MEDLINE, EMBASE, PsychINFO, CENTRAL, and ClinicalTrials.gov. The total number of references retrieved after duplicates were removed was 2,196. After 2 reviewers, working independently of each other, reviewed the abstracts and titles of these 2,196 references, the articles for 192 were selected and obtained for full-text review. This included 16 systematic reviews, for which the references of all included studies were examined for missing studies. Four additional studies were identified using this method. In total, 66 randomized controlled trials and 12 studies that evaluated drug safety were included in our analysis. Two nonconflicted panel members rated the class of evidence for each article according to the AAN scheme for classification of therapeutic articles (revised as denoted in a 2011 process manual amendment). Disagreements were resolved by a third panel member. Outcome data from included studies were extracted by the guideline methodologist and verified by a second panel member.

A repeat search was conducted in September 2017 to update our search results, with a total of 211 new abstracts retrieved after duplicate removal. Seven abstracts were selected for fulltext review, and 3 articles met our inclusion criteria and were added to the analysis.

The effect size, or standardized mean difference (SMD), was calculated for each study intervention/outcome pair. The SMD expresses the size of the intervention effect relative to the variability observed in each study. For our analysis, an SMD of 0.20 was considered the minimal clinically meaningful difference for reduction in tic severity; effect sizes smaller than 0.10 were considered clinically unimportant. There were a number of studies that did not provide adequate data to reliably calculate effect sizes. ${ }^{13-20}$ If multiple studies were available that evaluated the same intervention/ outcome pair, only those studies with the lowest risk of bias were used in formulating the confidence in evidence statements. A random effects meta-analysis was performed when appropriate to synthesize results of trials that studied the same intervention and outcome.

A modified form of the Grading of Recommendations Assessment, Development, and Evaluation (GRADE) process was used to develop conclusions. ${ }^{21}$ The confidence in the evidence (high, moderate, low, or very low) is anchored to the error domain-class of evidence, indirectness of evidence, and precision of effect estimate-with the highest risk of error (see unabridged practice guideline for complete details on the evidence synthesis process). 
Analysis of evidence

In children and adults with TS or a chronic tic disorder, which medical, behavioral, and neurostimulation interventions, compared with placebo or other active interventions, improve tic severity?

Unless otherwise specified, trial participants included both children (individuals aged 18 years and younger) and adults (individuals older than 18 years).

\section{High confidence in the evidence}

People with tics receiving the Comprehensive Behavioral Intervention for Tics are more likely than those receiving supportive psychotherapy to have reduced tic severity (SMD 0.56 ; $95 \%$ confidence interval $[\mathrm{CI}] 0.31-0.82$, high confidence, 2 Class I studies ${ }^{22,23}$ ).

\section{Moderate confidence in the evidence}

People with tics receiving the following interventions are probably more likely than those receiving placebo to have reduced tic severity:

- Haloperidol, SMD 0.59 (95\% CI 0.11-1.06), 2 Class II studies ${ }^{24,25}$

- $\quad$ Risperidone, SMD 0.79 (95\% CI 0.31-1.27), 2 Class II studies ${ }^{26,27}$

- Aripiprazole, SMD 0.64 (95\% CI 0.31-0.97), 1 Class I study $^{28}$ and 1 Class II study ${ }^{29}$ (children only)

- Tiapride, SMD 0.62 (95\% CI 0.36-0.88), 1 Class I study $^{30}$ (children only)

- Clonidine, SMD 0.45 (95\% CI 0.13-0.77), 1 Class I study $^{31}$ and 2 Class II studies ${ }^{32,33}$

- OnabotulinumtoxinA injections, SMD 1.27 (95\% CI 0.51-2.03), 1 Class II study ${ }^{34}$; confidence in evidence upgraded due to magnitude of effect

- $\quad$ Ningdong granule (as formulated by Zhao), SMD 0.97 (95\% CI 0.45-1.49), 1 Class II study ${ }^{35}$; confidence in evidence upgraded due to magnitude of effect (children only)

- $\quad$ 5-Ling granule, SMD 0.55 (95\% CI 0.33-0.76), 1 Class I study $^{30}$ (children only)

People with tics and a comorbid diagnosis of ADHD receiving the following interventions are probably more likely than those receiving placebo to have reduced tic severity:

- Clonidine plus methylphenidate, SMD 0.72 (95\% CI $0.22-1.22), 1$ Class I study ${ }^{31}$ (children only)

- Methylphenidate, SMD 0.61 (95\% CI 0.13-1.10), 1 Class I study $^{31}$ (children only)

- Desipramine, SMD 1.13 (95\% CI 0.47-1.79), 1 Class II study $^{36}$; confidence in evidence upgraded due to magnitude of effect (children only). Desipramine is now rarely used in children after several case reports of sudden death associated with the use of this medication. ${ }^{37}$
People with tics receiving active DBS of the globus pallidus are probably more likely than those receiving sham DBS of the globus pallidus to have reduced tic severity (SMD 0.77 [95\% CI 0.14-1.40], 2 Class II studies ${ }^{38,39}$ [adults only]).

\section{Low confidence in the evidence}

People with tics receiving the following interventions are possibly more likely than those receiving placebo to have reduced tic severity:

- Pimozide, SMD 0.66 (95\% CI 0.06-1.25), 3 Class II studies, ${ }^{24,40}$ confidence in evidence downgraded due to imprecision

- Ziprasidone, SMD 1.14 (95\% CI 0.32-1.97), 1 Class II study $^{41}$ (children only)

- Metoclopramide, SMD 1.14 (95\% CI 0.33-1.95), 1 Class II study ${ }^{42}$ (children only)

- Guanfacine, SMD 0.45 (95\% CI 0.03-0.87), 1 Class I study ${ }^{43}$ and 2 Class II studies, ${ }^{44,45}$ confidence in evidence downgraded due to imprecision (children only)

- Topiramate, SMD 0.91 (95\% CI 0.11-1.71), 1 Class II study $^{46}$

- Tetrahydrocannabinol, SMD 0.62 (95\% CI 0.01-1.22), 1 Class II study ${ }^{47}$ and 1 Class III study ${ }^{48}$ (adults only)

For people with tics and a comorbid diagnosis of $\mathrm{ADHD}$, atomoxetine does not worsen tics relative to placebo (1 Class II study ${ }^{49}$ ) (children only).

\section{Very low confidence in the evidence}

There is insufficient evidence to determine whether people with tics receiving the following interventions are more or less likely than those receiving placebo to have reduced tic severity:

- Baclofen, SMD 0.55 (95\% CI -0.39 to 1.49) 1 Class II study ${ }^{50}$; confidence in evidence downgraded due to imprecision (children only)

- Levetiracetam, SMD 0.22 (95\% CI -0.38 to 0.82 ), 1 Class II study ${ }^{51}$; confidence in evidence downgraded due to imprecision (children only)

- N-acetylcysteine, SMD 0.45 (95\% CI -0.27 to 1.17 ), 1 Class II study ${ }^{52}$; confidence in evidence downgraded due to imprecision (children only)

- Omega-3 fatty acids, SMD 0.69 (95\% CI 0.00-1.39), 1 Class II study ${ }^{53}$; confidence in evidence downgraded due to imprecision (children only)

- Ningdong granule (as formulated by Wang), 1 Class II study $^{17}$ (children only)

- Nicotine, SMD 0.38 (95\% CI -0.14 to 0.90 ), 1 Class III study $^{54}$ (children only)

- Nicotine patch added to haloperidol, SMD 0.71 (95\% CI $0.17-1.25), 1$ Class III study ${ }^{55}$ (children only)

- Mecamylamine, 1 Class II study ${ }^{16}$ (children only)

- Flutamide, 1 Class I study ${ }^{14}$ (adults only)

- Riluzole, SMD 0.17 (95\% CI -0.91 to 1.25), 1 Class I study ${ }^{56}$; confidence in evidence downgraded due to imprecision (children only) 
- D-serine, SMD -0.04 (95\% CI -1.13 to 1.05 ), 1 Class I study ${ }^{56}$; confidence in evidence downgraded due to imprecision (children only)

- Ondansetron, SMD 0.53 (95\% CI -0.20 to 1.25 ), 1 Class III study ${ }^{57}$

- Pramipexole, SMD 0.00 (95\% CI -0.53 to 0.53), 1 Class II study ${ }^{58}$; confidence in evidence downgraded due to imprecision (children only)

- IV immunoglobulin, SMD 0.50 (95\% CI -0.24 to 1.24 ), 1 Class II study ${ }^{59}$; confidence in evidence downgraded due to imprecision

- Deprenyl, SMD 0.47 (95\% CI -0.05 to 0.99), 1 Class II study ${ }^{60}$; confidence in evidence downgraded due to imprecision (children only)

There is insufficient evidence to determine whether people with tics receiving the following interventions are more or less likely than those receiving an alternate intervention to have reduced tic severity:

- Haloperidol vs pimozide, SMD 0.11 ( $95 \%$ CI -0.41 to 0.62), 2 Class II studies, ${ }^{24,25}$ confidence in evidence downgraded due to imprecision

- Risperidone vs pimozide, SMD 0.24 (95\% CI -0.51 to 0.99), 2 Class II studies, confidence in evidence downgraded due to imprecision

- Risperidone vs clonidine, SMD -0.19 (95\% CI -1.06 to $0.68), 1$ Class II study, ${ }^{\mathrm{e} 1}$ confidence in evidence downgraded due to imprecision (children only)

- Aripiprazole vs risperidone, SMD 0.17 (95\% CI -0.34 to $0.68), 1$ Class II study, ${ }^{\mathrm{e} 2}$ confidence in evidence downgraded due to imprecision (children only)

- Clonidine vs levetiracetam, SMD 0.86 (95\% CI -0.03 to 1.75), 1 Class II study ${ }^{\mathrm{e} 3}$ (children only)

- Habit reversal therapy vs exposure and response prevention, SMD 0.25 (95\% CI -0.40 to 0.90 ), 1 Class II study, ${ }^{\mathrm{e}}$ confidence in evidence downgraded due to imprecision

- Habit reversal therapy vs educational group treatments, SMD 0.55 (95\% CI -0.17 to 1.27 ), 1 Class II study, ${ }^{\text {es }}$ confidence in evidence downgraded due to imprecision (children only)

- Face-to-face habit reversal therapy vs habit reversal therapy through video conferencing, SMD 0.24 (95\% CI -0.70 to 1.18 ), 1 Class II study, ${ }^{\mathrm{e}}$ confidence in evidence downgraded due to imprecision (children only)

- Habit reversal therapy by video conferencing vs wait list control, SMD 0.24 (95\% CI -0.65 to 1.14 ), 1 Class II study, ${ }^{\mathrm{e} 7}$ confidence in evidence downgraded due to imprecision (children only)

- Relaxation therapy vs minimal therapy, 1 Class III study ${ }^{20}$ (children only)

- Biofeedback vs sham, 1 Class III study ${ }^{15}$ (adults only)

- Active DBS of the thalamus vs sham DBS of the thalamus, SMD 1.58 (95\% CI -0.12 to 3.28), 1 Class III study ${ }^{\mathrm{e}}$ (adults only)

- Active DBS of the centromedian-parafascicular complex vs sham DBS of the centromedian-parafascicular complex,
SMD 0.99 (95\% CI -0.28 to 2.26), 1 Class III study ${ }^{\mathrm{e} 9}$ (adults only)

- Continuous theta burst transcranial magnetic stimulation of the supplementary motor area vs sham transcranial magnetic stimulation, SMD -0.15 (95\% CI -1.29 to 0.99 ), 1 Class II study ${ }^{\mathrm{e} 10}$; confidence in evidence downgraded due to imprecision

- Repetitive transcranial magnetic stimulation (rTMS) of the supplementary motor area vs sham stimulation, SMD 0.19 (95\% CI -0.69 to 1.07), 1 Class II study, ${ }^{\text {el1 }}$ confidence in evidence downgraded due to imprecision (adults only)

- rTMS of the left motor or prefrontal cortex vs sham stimulation, 1 Class III study ${ }^{13}$

In children and adults with TS or a chronic tic disorder, what are the risks of harm, including weight gain, elevated prolactin levels, sedation, drug-induced movement disorders, hypotension, bradycardia, and ECG changes with medical treatments compared with placebo or other active interventions?

Data on harms related to the use of DBS can be found in the complete and unabridged practice guideline.

\section{Weight gain}

People with tics receiving risperidone are probably more likely to gain weight than people receiving placebo (moderate confidence, 2 Class II studies $^{27, \mathrm{e} 1}$ ).

People with tics receiving aripiprazole are probably more likely to gain weight than those receiving placebo (moderate confidence, 1 Class I study ${ }^{28}$ and I Class II study ${ }^{29}$ ) (children only).

People with tics receiving aripiprazole are possibly more likely to have an increase in body mass index and waist circumference than people receiving placebo (low confidence, I Class II study $^{29}$ ) (children only).

People with tics and a comorbid diagnosis of ADHD who are receiving atomoxetine are possibly more likely to have a decrease in body weight than people receiving placebo (low confidence, 1 Class II study ${ }^{49}$ ) (children only).

\section{Elevated prolactin levels}

People with tics receiving pimozide are possibly more likely to have increased prolactin levels than people receiving placebo (low confidence, 1 Class II study ${ }^{24}$ ).

People with tics receiving haloperidol are possibly more likely to have increased prolactin levels than people receiving placebo (low confidence, 1 Class II study ${ }^{24}$ ).

People with tics receiving metoclopramide are possibly more likely to have greater increases in prolactin levels than people receiving placebo (low confidence, 1 Class II study $^{42}$ ) (children only). 


\section{Sedation}

People with tics receiving risperidone are possibly more likely to experience fatigue and somnolence than people receiving placebo (low confidence, 1 Class II study ${ }^{26}$ ).

People with tics receiving aripiprazole are possibly more likely to experience sedation and somnolence than people receiving placebo (low confidence, 1 Class II study ${ }^{29}$ ) (children only).

People with tics receiving tiapride are probably more likely to experience higher rates of physical tiredness and sleep disturbances compared with people receiving placebo (moderate confidence, 1 Class I study ${ }^{30}$ ) (children only).

People with tics receiving clonidine are probably more likely to experience sedation than people receiving placebo (moderate confidence, 1 Class I study ${ }^{31}$ and 1 Class II study ${ }^{33}$ ).

People with tics receiving guanfacine are probably more likely than those receiving placebo to have drowsiness (moderate confidence, 1 Class I study ${ }^{43}$ ) (children only).

\section{Drug-induced movement disorders}

People with tics receiving pimozide are probably more likely to have extrapyramidal symptoms than people receiving placebo (moderate confidence, 2 Class II studies ${ }^{40}$ ).

People with tics receiving haloperidol are possibly more likely to have extrapyramidal symptoms than people receiving pimozide and placebo (low confidence, 1 Class II study ${ }^{24,25}$ ).

People with tics receiving risperidone are possibly more likely to have higher parkinsonism scores on the Extrapyramidal Symptom Rating Scale Score than people receiving placebo (low confidence, 1 Class II study ${ }^{26}$ ).

People with tics receiving risperidone are possibly more likely to require antiparkinsonian medication than people receiving placebo (low confidence, 1 Class II study ${ }^{26}$ ).

\section{Blood pressure}

People with tics and a comorbid diagnosis of ADHD receiving desipramine are possibly more likely to have an increase in diastolic blood pressure than people receiving placebo (low confidence, 1 Class II study ${ }^{36}$ ) (children only).

\section{Heart rate}

People with tics and a comorbid diagnosis of ADHD receiving atomoxetine are possibly more likely to have an increase in heart rate than people receiving placebo (low confidence, 1 Class II study ${ }^{49}$ ) (children only).

People with tics and a comorbid diagnosis of ADHD receiving desipramine are possibly more likely to have an increased heart rate than people receiving placebo (low confidence, 1 Class II study ${ }^{36}$ ) (children only).

\section{ECG changes}

People with tics receiving pimozide are possibly more likely to have a prolonged $\mathrm{QT}$ interval than people receiving placebo and haloperidol (low confidence, 1 Class II study ${ }^{25}$ ).

\section{Discussion}

This systematic review summarizes the evidence for efficacy and harms of interventions for the treatment of tics in individuals with TS and chronic tic disorders. While there is evidence to support the efficacy of several treatments, knowledge gaps remain. Many of the interventions have only been studied in one randomized controlled trial of short duration, with modest sample sizes. The inherent features of tic disorders, with waxing and waning of symptoms over time, placebo effects, as well as suppression of tics during clinical encounters, may confound symptom assessment in clinical trials. There remains a great need for randomized controlled trials of interventions for tics to further evaluate both longterm efficacy and safety. The accompanying practice guideline makes recommendations based on the findings of this systematic review, acknowledging the limitations of the currently available evidence and strongly encouraging psychoeducation and shared decision-making regarding treatment needs and priorities.

\section{Author contributions}

Dr. Pringsheim: study concept and design, acquisition of data, analysis or interpretation of data, drafting/revising the manuscript, critical revision of the manuscript for important intellectual content, study supervision. Dr. Holler-Managan: study concept and design, acquisition of data, analysis or interpretation of data, critical revision of the manuscript for important intellectual content. Dr. Okun: study concept and design, critical revision of the manuscript for important intellectual content. Dr. Jankovic: study concept and design, critical revision of the manuscript for important intellectual content. Dr. Piacentini: study concept and design, critical revision of the manuscript for important intellectual content. Dr. Cavanna: study concept and design, critical revision of the manuscript for important intellectual content. D. Martino: study concept and design, critical revision of the manuscript for important intellectual content. Dr. Müller-Vahl: study concept and design, critical revision of the manuscript for important intellectual content. Dr. Woods: study concept and design, critical revision of the manuscript for important intellectual content. M. Robinson: study concept and design, critical revision of the manuscript for important intellectual content. E. Jarvie: study concept and design, critical revision of the manuscript for important intellectual content. Dr. Roessner: study concept and design, critical revision of the manuscript for important intellectual content. Dr. Oskoui: study concept and design, acquisition of data, analysis or interpretation of data, critical revision of the manuscript for important intellectual content. This guideline was endorsed 
by the Child Neurology Society on September 4, 2018, and the European Academy of Neurology on September 5, 2018.

\section{Study funding}

This practice guideline was developed with financial support from the American Academy of Neurology (AAN). Authors who serve as AAN subcommittee members (Y.H.-M., M.O.) or as methodologists (T.P.), or who are AAN staff (S.M.), were reimbursed by the AAN for expenses related to travel to subcommittee meetings where drafts of manuscripts were reviewed.

\section{Disclosure}

T. Pringsheim has no disclosures to report. Y. HollerManagan has received funding for travel to the AAN and has served as member of an editorial advisory board for Neurology Now. M. Okun has declared nonfinancial support from the Parkinson's Foundation (PF) as National Medical Director; has received grants from the NIH, PF, Michael J. Fox Foundation (MJFF), and the Tourette Association of America (TAA); serves on the TAA Medical Advisory Board; is a member of the Board of Directors of Movement Disorders, Tremor and Hyperkinetic Disorders; has received royalties from publishing on Amazon, Smashwords, Taylor, Demos, and Books4Patients; has received continuing medical education speaker fees from Medscape/Web MD, Mededicus, PeerView, the AAN, and the Movement Disorders Society; provides clinical care for patients with Tourette syndrome; has received financial or material research support or compensation from the NIH, the PF, the MJFF, and the TAA; and has given expert testimony on medicolegal cases (approximately 10 years ago) but had no court appearances. J. Jankovic has served on advisory boards of, and received reimbursement for travel expenses from, Adamas Pharmaceuticals, Inc., Allergen, Inc., and Teva Pharmaceuticals Industries Ltd.; serves as a journal editor, an associate editor, or as a member of an editorial advisory board for Parkinson and Related Disorders, Acta Neurologica Scandinavica Journal of the Neurologic Sciences, Medlink, Neurotherapeutics, and Tremor and Other Hyperkinetic Movements; has received royalties from publishing with Cambridge, Elsevier, Future Science Group, Hodder Arnold, Lippincott Williams \& Wilkins, and WileyBlackwell; has received honoraria from Adamas Pharmaceuticals, Inc. and Teva Pharmaceuticals Industries Ltd.; has given botulinum neurotoxin injections; and has received research grants from Adamas Pharmaceutical, Inc. and Allergan, Inc. J. Piacentini has received funding for travel from the TLC Foundation for Body-Focused Repetitive Behaviors (BFRBs); has received travel funding and speaking honoraria from the TAA, the International Obsessive-Compulsive Disorder Foundation (IOCDF), the Karolinska Institutet, University of Modena, OCD New Jersey, New York University, the Child Mind Institute, the University of Southern Maine, Florida International University, and the Spanish Association for Child and Adolescent Psychiatry; has received royalties from Guilford Press and Oxford University Press; has performed behavior therapy for tics approximately $50 \%$ of his clinical time; and has received financial or material support from Pfizer Pharmaceuticals, the National Institute of Mental Health of the NIH, and from the academic entity of 501C3s, the TAA, TLC Foundation for BFRBs, and the Pettit Family Foundation. A. Cavanna has had nonfinancial competing interests at the Royal College of Psychiatrists, Faculty of Neuropsychiatry, Movement Disorders; has received funding for travel from the TAA; has served as a journal editor, an associate editor, or an editorial advisory board member for Behavioral Neurology and Epilepsy and Behavior; has received royalties from Oxford University Press; and has received personal compensation from speakers' bureaus with UCB Pharma, Eisai, and Janssen-Cilag. D. Martino has no disclosures to report. K. Müller-Vahl has nonfinancial competing interests as a member of the TAA medical advisory board, the scientific advisory board of the German Tourette Association (TGD), the board of directors of the German (ACM) and the International (IACM) Association for Cannabinoid Medicines, and the committee of experts for narcotic drugs at the federal opium bureau of the Federal Institute for Drugs and Medical Devices (BfArM) in Germany; has received consultant's honoraria from Abide Therapeutics, Fundacion Canna, and Therapix Biosiences, and speaker's fees from Tilray, and is a consultant for Zynerba Pharmaceuticals; has served as a guest editor for Frontiers in Neurology on the research topic "The neurobiology and genetics of Gilles de la Tourette syndrome: new avenues through large-scale collaborative projects" and is an associate editor for Cannabis and Cannabinoid Research; has performed several clinical studies related to Tourette syndrome, including randomized controlled trials using cannabinoids and behavioral therapy; has received financial or material research support from the German Ministry of Education and Research (BMBF), German Research Society (Deutsche Forschungsgemeinschaft [DFG]), European Union, Tourette Gesellschaft Deutschland e.V., Else-Kroner-Fresenius-Stiftung, and GW, Almirall, Abide Therapeutics, and Therapix Biosiences; and has received royalties from Medizinisch Wissenschaftliche Verlagsgesellschaft Berlin. D. Woods has a nonfinancial competing interest as a member of the TAA Medical Advisory Board; has received royalties from Guilford Press, Oxford University Press, and Springer Press; and has received honoraria from speaking from the TAA. M. Robinson has a nonfinancial competing interest in serving as co-Chair for the Massachusetts State Chapter of the Tourette Association of America Board of Directors. E. Jarvie has declared a nonfinancial competing interest in serving as member of the Wisconsin Tourette Syndrome Association Board of Directors. V. Roessner serves on an advisory board for the German Tourette Society and the German Society of ObsessiveCompulsive Disorder; has received funding for travel from Actelion, Lilly, MEDICE, Novartis, and Shire; serves as a journal editor, associate editor, or member of an advisory board for European Child and Adolescent Psychiatry, Zeitschrift fur Kinder- und Jugendpsychiatrie, Neuropsychiatrie, Behavioral Neurology, and Scientific Reports; has received honoraria from Actelion, Lilly, MEDICE, Novartis, and Shire; has received 
financial or material research support or compensation from the government entities of the European Union, DFG, $\mathrm{BMBF}$, and KSV Sachsen; and has received support from academic entities such as Tourette Gesellschaft Deutschland e.V., Roland-Ernst-Stiftung, Friede-Springer-Stiftung, and Else-Kroner-Fresenius-Stiftung, and from commercial entities such as Novartis. M. Oskoui has received funding for travel from the AAN; has received research support from the government entities of Fonds de Recherche Sante du Québec, Canada Institute of Health Research, McGill University Research Institute, the SickKids Foundation, Cerebral Palsy Alliance Foundation, and Kids Brain Health Network for research in cerebral palsy; serves on the data safety monitoring board for Avexis; has received financial compensation for consulting work for Biogen and Roche; and has received research support as site PI for Ionis, Biogen, Roche, and Cytokinetics for clinical trials in spinal muscular atrophy. Go to Neurology.org/N for full disclosures.

\section{Disclaimer}

Practice guidelines, practice advisories, comprehensive systematic reviews, focused systematic reviews, and other guidance published by the AAN and its affiliates are assessments of current scientific and clinical information provided as an educational service. The information: (1) should not be considered inclusive of all proper treatments, methods of care, or as a statement of the standard of care; (2) is not continually updated and may not reflect the most recent evidence (new evidence may emerge between the time information is developed and when it is published or read); (3) addresses only the question(s) specifically identified; (4) does not mandate any particular course of medical care; and (5) is not intended to substitute for the independent professional judgment of the treating provider, as the information does not account for individual variation among patients. In all cases, the selected course of action should be considered by the treating provider in the context of treating the individual patient. Use of the information is voluntary. AAN provides this information on an "as is" basis, and makes no warranty, expressed or implied, regarding the information. AAN specifically disclaims any warranties of merchantability or fitness for a particular use or purpose. AAN assumes no responsibility for any injury or damage to persons or property arising out of or related to any use of this information or for any errors or omissions.

\section{Conflict of interest}

The AAN is committed to producing independent, critical, and truthful clinical practice guidelines (CPGs). Significant efforts are made to minimize the potential for conflicts of interest to influence the recommendations of this CPG. To the extent possible, the AAN keeps separate those who have a financial stake in the success or failure of the products appraised in the CPGs and the developers of the guidelines. Conflict of interest forms were obtained from all authors and reviewed by an oversight committee prior to project initiation. AAN limits the participation of authors with substantial conflicts of interest. The AAN forbids commercial participation in, or funding of, guideline projects. Drafts of the guideline have been reviewed by at least 3 AAN committees, a network of neurologists, Neurology peer reviewers, and representatives from related fields. The AAN Guideline Author Conflict of Interest Policy can be viewed at www.aan.com. For complete information on this process, access the 2011 AAN process manual, as amended. ${ }^{11}$

\section{Publication history}

Received by Neurology June 15, 2018. Accepted in final form November 24, 2018 .

\section{References}

1. American Psychiatric Association, DSM-5 Task Force. Diagnostic and Statistical Manual of Mental Disorders: DSM-5 ${ }^{\mathrm{TM}}$, 5th ed. Arlington: American Psychiatric Publishing; 2013.

2. Cavanna AE, Seri S. Tourette's syndrome. BMJ 2013;347:f4964.

3. Robertson MM, Eapen V, Singer HS, et al. Gilles de la Tourette syndrome. Nat Rev Dis Primers 2017;3:16097.

4. Knight T, Steeves T, Day L, Lowerison M, Jette N, Pringsheim T. Prevalence of tic disorders: a systematic review and meta-analysis. Pediatr Neurol 2012;47:77-90.

5. Yang J, Hirsch L, Martino D, Jette N, Roberts J, Pringsheim T. The prevalence of diagnosed Tourette syndrome in Canada: a national population-based study. Mov Disord 2016;31:1658-1663.

6. Cavanna AE, Rickards H. The psychopathological spectrum of Gilles de la Tourette syndrome. Neurosci Biobehav Rev 2013;37:1008-1015.

7. Hirschtritt ME, Lee PC, Pauls DL, et al. Lifetime prevalence, age of risk, and genetic relationships of comorbid psychiatric disorders in Tourette syndrome. JAMA Psychiatry $2015 ; 72: 325-333$

8. Frank MC, Piedad J, Rickards H, Cavanna AE. The role of impulse control disorders in Tourette syndrome: an exploratory study. J Neurol Sci 2011;310:276-278.

9. Eddy CM, Cavanna AE, Gulisano M, Cali P, Robertson MM, Rizzo R. The effects of comorbid obsessive-compulsive disorders and attention-deficit hyperactivity disorder on quality of life in Tourette syndrome. J Neuropsychiatry Clin Neurosciences 2012; 24:458-462.

10. Cavanna AE, David K, Bandera V, et al. Health-related quality of life in Gilles de la Tourette syndrome $=$ a decade of research. Behav Neurol 2013;27:83-93.

11. American Academy of Neurology. Clinical Practice Guideline Process Manual, 2011. St. Paul: The American Academy of Neurology; 2011.

12. Martino D, Pringsheim TM, Cavanna AE, et al. Systematic review of severity scales and screening instruments for tics: critique and recommendations. Mov Disord 2017; 32:467-473.

13. Chae JH, Nahas Z, Wassermann E, et al. A pilot safety study of repetitive transcranial magnetic stimulation (rTMS) in Tourette's syndrome. Cogn Behav Neurol 2004;17: 109-117.

14. Peterson BS, Zhang H, Anderson GM, Leckman JF. A double-blind, placebocontrolled, crossover trial of an antiandrogen in the treatment of Tourette's syndrome. J Clin Psychopharmacol 1998;18:324-331.

15. Nagai Y, Cavanna AE, Critchley HD, Stern JJ, Robertson MM, Joyce EM. Biofeedback treatment for Tourette syndrome: a preliminary randomized controlled trial. Cogn Behav Neurol 2014;27:17-24.

16. Silver AA, Shytle RD, Sheehan KH, Sheehan DV, Ramos A, Sanberg PR. Multicenter, double-blind, placebo-controlled study of mecamylamine monotherapy for Tourette's disorder. J Am Acad Child Adolesc Psychiatry 2001;40:1103-1110.

17. Wang S, Qi F, Li J, Zhao L, Li A. Effects of Chinese herbal medicine Ningdong granule on regulating dopamine (DA)/serotonin (5-TH) and gamma-amino butyric acid (GABA) in patients with Tourette syndrome. Biosci Trends 2012;6:212-218.

18. Singer HS, Brown J, Quaskey S, Rosenberg LA, Mellits ED, Denckla MB. The treatment of attention-deficit hyperactivity disorder in Tourette's syndrome: a double-blind placebo-controlled study with clonidine and desipramine. Pediatrics 1995 95:74-81.

19. Castellanos FX, Giedd JN, Elia J, et al. Controlled stimulant treatment of ADHD and comorbid Tourette's syndrome: effects of stimulant and dose. J Am Acad Child Adolesc Psychiatry 1997;36:589-596.

20. Bergin A, Waranch HR, Brown J, Carson K, Singer HS. Relaxation therapy in Tourette syndrome: a pilot study. Pediatr Neurol 1998;18:136-142.

21. Guyatt G, Oxman AD, Akl EA, et al. GRADE guidelines: 1: Introduction-GRADE evidence profiles and summary of findings tables. J Clin Epidemiol 2011;64:383-394.

22. Piacentini J, Woods DW, Scahill L, et al. Behavior therapy for children with Tourette disorder: a randomized controlled trial. JAMA 2010;303:1929-1937.

23. Wilhelm S, Peterson AL, Piacentini J, et al. Randomized trial of behavior therapy for adults with Tourette syndrome. Arch Gen Psychiatry 2012;69:795-803.

24. Sallee FR, Nesbitt L, Jackson C, Sine L, Sethuraman G. Relative efficacy of haloperidol and pimozide in children and adolescents with Tourette's disorder. Am J Psychiatry 1997; 154:1057-1062.

25. Shapiro E, Shapiro AK, Fulop G, et al. Controlled study of haloperidol, pimozide and placebo for the treatment of Gilles de la Tourette's syndrome. Arch Gen Psychiatry 1989;46:722-730. 
Disperidone in the treatment of Tourette syndrome: a double-blind, placebo-controlled trial. J Clin Psychopharmacol 2002;22 31-39.

27. Scahill L, Leckman JF, Schultz RT, Katsovich L, Peterson BS. A placebo-controlled trial of risperidone in Tourette syndrome. Neurology 2003;60:1130-1135.

28. Sallee F, Kohegyi E, Zhao J, et al. Randomized, double-blind, placebo-controlled trial demonstrates the efficacy and safety of oral aripiprazole for the treatment of Tourette's disorder in children and adolescents. J Child Adolesc Psychopharmacol 2017; 27:771-781.

29. Yoo HK, Joung YS, Lee JS, et al. A multicenter, randomized, double-blind, placebocontrolled study of aripiprazole in children and adolescents with Tourette's disorder. J Clin Psychiatry 2013;74:e772-e780.

30. Zheng Y, Zhang ZJ, Han XM, et al. A proprietary herbal medicine (5-ling granule) for Tourette syndrome: a randomized controlled trial. J Child Psychol Psychiatry 2016; 57:74-83.

31. Tourette's Syndrome Study Group. Treatment of ADHD in children with tics: a randomized controlled trial. Neurology 2002;58:527-536.

32. Du YS, Li HF, Vance A, et al. Randomized double-blind multicentre placebocontrolled clinical trial of the clonidine adhesive patch for the treatment of tic disorders. Aust NZ J Psychiatry 2008;42:807-813.

33. Leckman JF, Hardin MT, Riddle MA, Stevenson J, Ort SI, Cohen DJ. Clonidine treatment of Gilles de la Tourette's syndrome. Arch Gen Psychiatry 1991;48:324-328.

34. Marras C, Andrews D, Sime E, Lang AE. Botulinum toxin for simple motor tics: a randomized, double-blind, controlled clinical trial. Neurology 2001;56:605-610.

35. Zhao L, Li AY, Lv H, Liu FY, Qi FH. Traditional Chinese medicine Ningdong granule: the beneficial effects in Tourette's disorder. J Int Med Res 2010;38:169-175.

36. Spencer T, Biederman J, Coffey B, et al. A double-blind comparison of desipramine and placebo in children and adolescents with chronic tic disorder and comorbid attention-deficit/hyperactivity disorder. Arch Gen Psychiatry 2002;59:649-656.

37. Riddle MA, Geller B, Ryan N. Another sudden death in a child treated with desipramine. J Am Acad Child Adolesc Psychiatry 1993;32:792-797.

38. Kefalopoulou Z, Zrinzo L, Jahanshahi M, et al. Bilateral globus pallidus stimulation for severe Tourette's syndrome: a double-blind, randomised crossover trial. Lancet Neurol 2015;14:595-605.

39. Welter ML, Houeto JL, Thobois S, et al. Anterior pallidal deep brain stimulation for Tourette's syndrome: a randomised, double-blind, controlled trial. Lancet Neurol 2017;16:610-619.

40. Shapiro AK, Shapiro E. Controlled study of pimozide vs placebo in Tourette's syndrome. J Am Acad Child Psychiatry 1984;23:161-173.

41. Sallee FR, Kurlan R, Goetz CG, et al. Ziprasidone treatment of children and adolescents with Tourette's syndrome: a pilot study. J Am Acad Child Adolesc Psychiatry 2000;39:292-299.

42. Nicolson R, Craven-Thuss B, Smith J, McKinlay BD, Castellanos FX. A randomized, double-blind, placebo-controlled trial of metoclopramide for the treatment of Tourette's disorder. J Am Acad Child Adolesc Psychiatry 2005;44:640-646.

43. Murphy TK, Fernandez TV, Coffey BJ, et al. Extended-release guanfacine does not show a large effect on tic severity in children with chronic tic disorders. J Child Adolesc Psychopharmacol 2017;27:762-770.
44. Scahill L, Chappell PB, Kim YS, et al. A placebo-controlled study of guanfacine in the treatment of children with tic disorders and attention deficit hyperactivity disorder. Am J Psychiatry 2001;158:1067-1074.

45. Cummings DD, Singer HS, Krieger M, Miller TL, Mahone EM. Neuropsychiatric effects of guanfacine in children with mild Tourette syndrome: a pilot study. Clin Neuropharmacology 2002;25:325-332.

46. Jankovic J, Jimenez-Shahed J, Brown LW. A randomised, double-blind, placebocontrolled study of topiramate in the treatment of Tourette syndrome. J Neuro Neurosurg Psychiatry 2010;81:70-73.

47. Muller-Vahl KR, Schneider U, Koblenz A, et al. Treatment of Tourette's syndrome with delta 9-tetrahydrocannabinol (THC): a randomized crossover trial. Pharmacopsychiatry 2002;35:57-61.

48. Muller-Vahl KR, Schneider U, Prevedel H, et al. Delta 9-tetrahydrocannabinol (THC) is effective in the treatment of tics in Tourette syndrome: a 6-week randomized trial. J Clin Psychiatry 2003;64:459-465.

49. Allen AJ, Kurlan RM, Gilbert DL, et al. Atomoxetine treatment in children and adolescents with ADHD and comorbid tic disorders. Neurology 2005;65:1941-1949.

50. Singer HS, Wendlandt J, Krieger M, Giuliano J. Baclofen treatment in Tourette syndrome: a double-blind, placebo-controlled, crossover trial. Neurology 2001;56:599-604.

51. Smith-Hicks CL, Bridges DD, Paynter NP, Singer HS. A double blind randomized placebo control trial of levetiracetam in Tourette syndrome. Mov Disord 2007;22: 1764-1770.

52. Bloch MH, Panza KE, Yaffa A, et al. N-acetylcysteine in the treatment of pediatric Tourette syndrome: randomized, double-blind, placebo-controlled add-on trial. J Child Adolesc Psychopharmacol 2016;26:327-334.

53. Gabbay V, Babb JS, Klein RG, et al. A double-blind, placebo-controlled trial of omega3 fatty acids in Tourette's disorder. Pediatrics 2012;129:e1493-e1500.

54. Howson AL, Batth S, Ilivitsky V, et al. Clinical and attentional effects of acute nicotine treatment in Tourette's syndrome. Eur Psychiatry 2004;19:102-112.

55. Silver AA, Shytle RD, Philipp MK, Wilkinson BJ, McConville B, Sanberg PR Transdermal nicotine and haloperidol in Tourette's disorder: a double-blind placebocontrolled study. J Clin Psychiatry 2001;62:707-714.

56. Lemmon ME, Grados M, Kline T, Thompson CB, Ali SF, Singer HS. Efficacy of glutamate modulators in tic suppression: a double-blind, randomized control trial of D-serine and riluzole in Tourette syndrome. Pediatr Neurol 2015;52:629-634.

57. Toren P, Weizman A, Ratner S, Cohen D, Laor N. Ondansetron treatment in Tourette's disorder: a 3-week, randomized, double-blind, placebo-controlled study. J Clin Psychiatry 2005;66:499-503.

58. Kurlan R, Crespi G, Coffey B, Mueller-Vahl K, Koval S, Wunderlich G. A multicente randomized placebo-controlled clinical trial of pramipexole for Tourette's syndrome. Mov Disord 2012;27:775-778.

59. Hoekstra PJ, Minderaa RB, Kallenberg CG. Lack of effect of intravenous immunoglobulins on tics: a double-blind placebo-controlled study. J Clin Psychiatry 2004;65: 537-542.

60. Feigin A, Kurlan R, McDermott MP, et al. A controlled trial of deprenyl in children with Tourette's syndrome and attention deficit hyperactivity disorder. Neurology 1996;46:965-968

References e1-e11 are available at links.lww.com/WNL/A883.

\section{Subspecialty Alerts by E-mail!}

Customize your online journal experience by signing up for e-mail alerts related to your subspecialty or area of interest. Access this free service by clicking on the "My Alerts" link on the home page. An extensive list of subspecialties, methods, and study design choices will be available for you to choose from-allowing you priority alerts to cutting-edge research in your field!

\section{Did You Know...}

... you can browse by subspecialty topics on Neurology.org?

Go to: Neurology.org and click on "Topics" in the top navigation bar. 


\section{Neurology}

\section{Comprehensive systematic review summary: Treatment of tics in people with Tourette syndrome and chronic tic disorders \\ Tamara Pringsheim, Yolanda Holler-Managan, Michael S. Okun, et al. \\ Neurology 2019;92;907-915 \\ DOI 10.1212/WNL.0000000000007467}

\section{This information is current as of May 6, 2019}

\section{Updated Information \& Services}

\section{References}

Citations

\section{Subspecialty Collections}

Errata

Permissions \& Licensing

\section{Reprints}

including high resolution figures, can be found at: http://n.neurology.org/content/92/19/907.full

This article cites 58 articles, 8 of which you can access for free at: http://n.neurology.org/content/92/19/907.full\#ref-list-1

This article has been cited by 1 HighWire-hosted articles: http://n.neurology.org/content/92/19/907.full\#\#otherarticles

This article, along with others on similar topics, appears in the following collection(s):

\section{ADHD}

http://n.neurology.org/cgi/collection/adhd

Botulinum toxin

http://n.neurology.org/cgi/collection/botulinum_toxin

Tics

http://n.neurology.org/cgi/collection/tics

Tourette syndrome

http://n.neurology.org/cgi/collection/tourette_syndrome

An erratum has been published regarding this article. Please see next page or:

/content/93/9/415.4.full.pdf

Information about reproducing this article in parts (figures,tables) or in its entirety can be found online at:

http://www.neurology.org/about/about_the_journal\#permissions

Information about ordering reprints can be found online:

http://n.neurology.org/subscribers/advertise

Neurology ${ }^{\circledR}$ is the official journal of the American Academy of Neurology. Published continuously since 1951, it is now a weekly with 48 issues per year. Copyright (O 2019 American Academy of Neurology. All rights reserved. Print ISSN: 0028-3878. Online ISSN: 1526-632X.

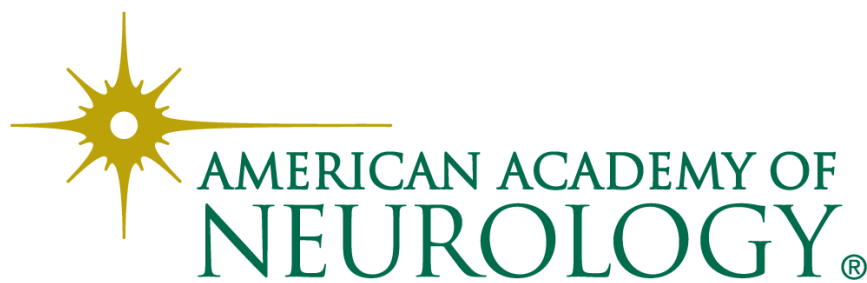




\section{Teaching NeuroImages: The zigzag edging sign of adult-onset neuronal intranuclear inclusion disease}

Neurology ${ }^{\circledR}$ 2019;93:415. doi:10.1212/WNL.0000000000007922

In the article "Teaching NeuroImages: The zigzag edging sign of adult-onset neuronal intranuclear inclusion disease" by Chen et al., ${ }^{1}$ the second-to-last sentence in the first paragraph should read "FMR1 CGG permutation was not present." The publisher regrets the error.

\section{Reference}

1. Chen L, Chen A, Lei S, et al. Teaching NeuroImages: The zigzag edging sign of adult-onset neuronal intranuclear inclusion disease. Neurology 2019;92:e2295-e2296.

\section{Opinion and Special Articles: Self-management in epilepsy}

Web-based seizure tracking applications

Neurology ${ }^{\circledR}$ 2019;93:415. doi:10.1212/WNL.0000000000007480

In the article "Opinion and Special Articles: Self-management in epilepsy: Web-based seizure tracking applications" by Casassa et al., ${ }^{1}$ first published online November 19, 2018, NIH Grant T32NS048005 should have been listed as a funding source. The authors regret the error.

\section{Reference}

1. Casassa C, Rathbun Levit E, Goldenholz DM. Opinion and Special Articles: Self-management in epilepsy: web-based seizure tracking applications. Neurology 2018;91:e2027-e2030.

\section{Cost of illness in Charcot-Marie-Tooth neuropathy}

Results from Germany

Neurology ${ }^{\circledR}$ 2019;93:415. doi:10.1212/WNL.0000000000007916

In the article "Cost of illness in Charcot-Marie-Tooth neuropathy: Results from Germany" by Schorling et al., ${ }^{1}$ first published online March 27, 2019, the published-online-ahead-of-print version should have presented figures in USD rather than euros. They are presented correctly in the April 23 issue. The editorial office regrets the error.

\section{Reference}

1. Schorling E, Thiele S, Gumbert L, et al. Cost of illness in Charcot-Marie-Tooth neuropathy: results from Germany. Neurology 2019;92: e2027-e2037.

\section{Comprehensive systematic review summary: Treatment of tics in people with Tourette syndrome and chronic tic disorders Neurology ${ }^{\circledR}$ 2019;93:415. doi:10.1212/WNL.0000000000007918}

In the article "Comprehensive systematic review summary: Treatment of tics in people with Tourette syndrome and chronic tic disorders" by Pringsheim et al., ${ }^{1}$ first published online May 6, 2019, the data supplement link in the first paragraph should have been: links.lww.com/ WNL/A882. The authors regret the error.

\section{Reference}

1. Pringsheim T, Holler-Managan Y, Okun MS, et al. Comprehensive systematic review summary: Treatment of tics in people with Tourette syndrome and chronic tic disorders. Neurology 2019; 92:907-915. 